\title{
Evaluation of Glucocorticoid Faecal Monitoring as a Non-Invasive Assessment of Stress in Captive Crab-Eating Fox (Cerdocyoun thous) After ACTH Stimulation
}

\author{
Regina Celia Rodrigues da Paz ${ }^{1 *}$, Nely Pinheiro Souza ${ }^{1}$ and Janine L Brown ${ }^{2}$ \\ ${ }^{1}$ College of Agronomy, Veterinary and Zootechny, Federal University of Mato Grosso, Cuiabá/MT, Brazil
}

${ }^{2}$ Smithsonian Conservation Biology Institute, National Zoological Park, Front Royal, VA, USA

"Corresponding author: Regina Celia Rodrigues da Paz, Associate Professor of Basic Sciences, College of Agronomy, Veterinary and Zootechny, Federal University of Mato Grosso, Avenida Fernando Correa da Costa, CEP 78060-900, Cuiabá/MT, Brazil, Tel: +55 6536158614 ; Fax: +5565 36158627; E-mail: reginacrpaz@gmail.com

Rec date: Feb20, 2014; Acc date: Mar 29, 2014; Pub date: Apr 05, 2014

Copyright: (c) 2014 Rodrigues da Paz RC, et al. This is an open-access article distributed under the terms of the Creative Commons Attribution License, which permits unrestricted use, distribution, and reproduction in any medium, provided the original author and source are credited.

\begin{abstract}
Blood sampling is a common method in biological research of domestic animals for studying hormone mechanisms. However, this approach can be stressful for wild species, and compromise research concerning animal welfare. The crab-eating fox (Cerdocyoun thous) is a medium-sized canid found in South America and a popular zoo species in that region. However, almost nothing is known of their biology or what factors impact captive welfare. Thus, a non-invasive method to measure adrenal activity and stress was developed for quantifying fecal glucocorticoids non-invasively in this species. The physiological relevance of the cortisol immunoassay was demonstrated by injection of exogenous ACTH into two males and one female, which led to a significant increase in fecal glucocorticoid metabolites within $24-48 \mathrm{~h}$. From these findings we conclude that fecal samples can be used for the non-invasive assessment of adrenocortical status in crab-eating fox.
\end{abstract}

Keywords: Feces; Cortisol; Corticosterone; Stress; Non-invasively method; Enzyme immunoassay; ACTH challenge

\section{Introduction}

The crab-eating fox (Cerdocyoun thous) is a medium-sized canid found in Colombia, Venezuela, Guyana, French Guyana, Surinam, eastern Peru, eastern Bolivia, Paraguay, Uruguay, Northern Argentina and in most of Brazil outside the lowlands of the Amazon basin [1]. Their range includes subtropical and tropical savannas as well as riperian forest areas. The species is socially monogomous, and the adult female gives birth to one or two litters per year after a 58-60-day gestation [2]. As the name implies, the diet includes crabs caught on muddy floodplains during the wet season, as well as insects, rodents and birds when available, and fruits, and the species plays an important role as seed dispersers and controlling rodent populations [3-6]. No precise estimates of population sizes are available in Brazil, but populations generally are considered stable and adaptable to deforestation, agricultural and horticultural development (e.g., sugarcane, eucalyptus, melon, pineapples) and habitats in regeneration [3]. However, the fox is perceived as a pest of poultry throughout much of its range (and in Uruguay as a predator of lambs), and they are thus shot, trapped, and poisoned indiscriminately.

Measures of circulating cortisol have been widely used to evaluate stress responses in domestic animals. However, blood sampling techniques often are not applicable to studies of wildlife species. For example, capture and handling of animals for venipuncture can induce a stress response, with increased peripheral glucocorticoid concentrations observed within minutes [7]. Due to the increasing demand for methods to quantify adrenal activity in zoo and wild animals in response to mate introduction and transportation, after pharmacological and management precautions to minimize stress, and the necessity to investigate stress impacts on animal welfare, noninvasively methods for measuring adrenal activity have been developed for a variety of species: primates [8,9]; ruminants $[10,11]$; several felids [12-14]; African wild dog [15].

Glucocorticoids are extensively metabolized by the liver, and excretions of glucocorticoid metabolites can differ among species, and sometimes even between sexes and individuals within a given species [16]. The lag time between glucocorticoid secretion from the adrenal gland and excretion into feces or urine also tends to be fairly speciesspecific [16-19]. Therefore, it is not always possible to draw on data from other species to develop non-invasively approaches for assessing adrenal function in an unstudied species. Thus, the aims of this study were to validate an enzyme immunoassay to quantify glucocorticoid metabolites in feces of crab-eating fox. The first goal was to show that fecal glucocorticoid metabolite concentrations increase after an ACTH challenge [19].

\section{Materials and Methods}

\section{Animals}

Two female (F4 and F5) and two males (M1 and M2) crab-eating foxes were used for ACTH challenges. Permission for animal use was 
Citation: Rodrigues da Paz RC, Souza NP, Brown JL (2014) Evaluation of Glucocorticoid Faecal Monitoring as a Non-Invasive Assessment of Stress in Captive Crab-Eating Fox (Cerdocyoun thous) After ACTH Stimulation. J Steroids Hormon Sci S12: 008. doi: 10.4172/2157-7536.S12-008

Page 2 of 3

approved by the SISBIO/IBAMA/Brazil $\left(\mathrm{n}^{0} 11167-1\right)$ and CEPA/ UFMT Bioetical Committee ( $\left.{ }^{0} 23108.002900 / 09-3\right)$.

Animals were housed at the Universidade Federal de Mato Grosso

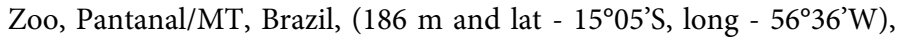
which has a tropical climate [20].

The animals were fed twice a daily (morning and afternoon), a diet of fruits (papaya, banana), fish or meat, commercial dog food and a food coloring dye added to a ground meat once a daily (morning) to identify individual feces. Water was provided ad libitum. Individual fecals were identified by visualization with tail tricotomy and feeding dye.

\section{Experimental Design}

During the ACTH challenge the animals were housed in two separate enclosures. Three animals (M1, M2, F5) were injected with $0.2 \mathrm{~mL}$ of adrenocorticotropic hormone (ACTH; Synacthen; Novartis Pharma AG, Basel, Switzerland, $1 \mathrm{mg} / \mathrm{mL}$ ) intra-muscularly. A control animal (F4) was injected with $0.2 \mathrm{~mL}$ saline, intra-muscularly. Fecals samples were collected for 6 days before and 6 days after injection. All samples were immediately stored at $-22^{\circ} \mathrm{C}$ until analyses.

\section{Fecal Steroid Analyses}

Extraction of fecal samples followed the procedure described by Schwarzenberger et al. [21], with minor modifications. Fecal samples were thawed and mixed. For each sample, $0.5 \mathrm{~g}$ of homogenized wet feces was suspended in $5 \mathrm{~mL}$ of $80 \%$ methanol and homogenized. Tubes were vortexed (30 s) and gently homogenized for $15 \mathrm{~h}$. Subsequently, samples were centrifuged $(1,300 \mathrm{~g}$ for $15 \mathrm{~min})$ and the supernatant kept in a water bath at $60^{\circ} \mathrm{C}$ until total evaporation of the $80 \%$ methanol. The samples were suspended in $1 \mathrm{~mL}$ dilution buffer [ $\mathrm{NaH}_{2} \mathrm{PO}_{4}(5.4 \mathrm{~g}), \mathrm{Na}_{2} \mathrm{HPO}_{4}$ (8.66 g), $\mathrm{NaCl}(8.7 \mathrm{~g}), \mathrm{H}_{2} \mathrm{O}$ Mili-Q (1 L), $\mathrm{pH}$ (7.0)], $\mathrm{pH}$ (7.0)] and vortexed for about $1 \mathrm{~min}$. An aliquot of the supernatant was diluted with dilution buffer (final dilution: 1:30) and frozen at $-22^{\circ} \mathrm{C}$ until EIA analysis.

For the cortisol EIA, $50 \mu \mathrm{l}$ of cortisol R4866 antibody (Coralie Munro, UC Davis, California) in coating buffer $\left[\mathrm{Na}_{2} \mathrm{CO}_{3}(1.59 \mathrm{~g})\right.$, $\mathrm{NaHCO}_{3}(2.93 \mathrm{~g}), \mathrm{H}_{2} \mathrm{O}$ Mili-Q (1 L), pH (9.6)] (1:8500) was pipetted onto NUNC microtitre plates and incubated overnight at $5^{\circ} \mathrm{C}$. Plates were washed five times with MilliQH2O/Tween 20 (1:500,000), then standards (3.9 - $1000 \mathrm{pg} /$ well), low and high controls, each sample in duplicate and cortisol HRP (Coralie Munro) in assay buffer [Tris $(2.42$ g), $\mathrm{NaCl}(17.9 \mathrm{~g}), \mathrm{BSA}(1 \mathrm{~g})$, Tween 80 (1 mL) H2O Mili-Q (1 L), pH (7.5)] $(1: 20,000)$ was pipetted into the microtiter plate wells and incubated for $1 \mathrm{~h}$ at room temperature. Plates were washed again with MilliQH $\mathrm{H}_{2} \mathrm{O}$ /Tween 20 and $100 \mu \mathrm{l}$ of $40 \mu \mathrm{l} 0.5 \mathrm{H}_{2} \mathrm{O}_{2}, 125 \mu \mathrm{l} 40 \mathrm{mM}$ ABTS and $12.5 \mathrm{ml}$ substrate buffer was added to each well. The absorbance was measured at $450 \mathrm{~nm} / 540 \mathrm{~nm}$, using a DYNEX MRX reader (Dynex Technologies, Chantilly, VA, USA).

\section{Results and Discussion}

Administration of ACTH resulted in a 10 to 45 -fold increase in fecal glucocorticoid metabolite concentrations in all animals, which peaked within a day of injection (Figure 1, Table 1). Following the ACTH injection, fecal metabolite concentrations peaked after 24-48 h and then returned to baseline within $24 \mathrm{~h}$ of the peak. Concentrations were unchanged in the saline-treated control animal (Figure 1).

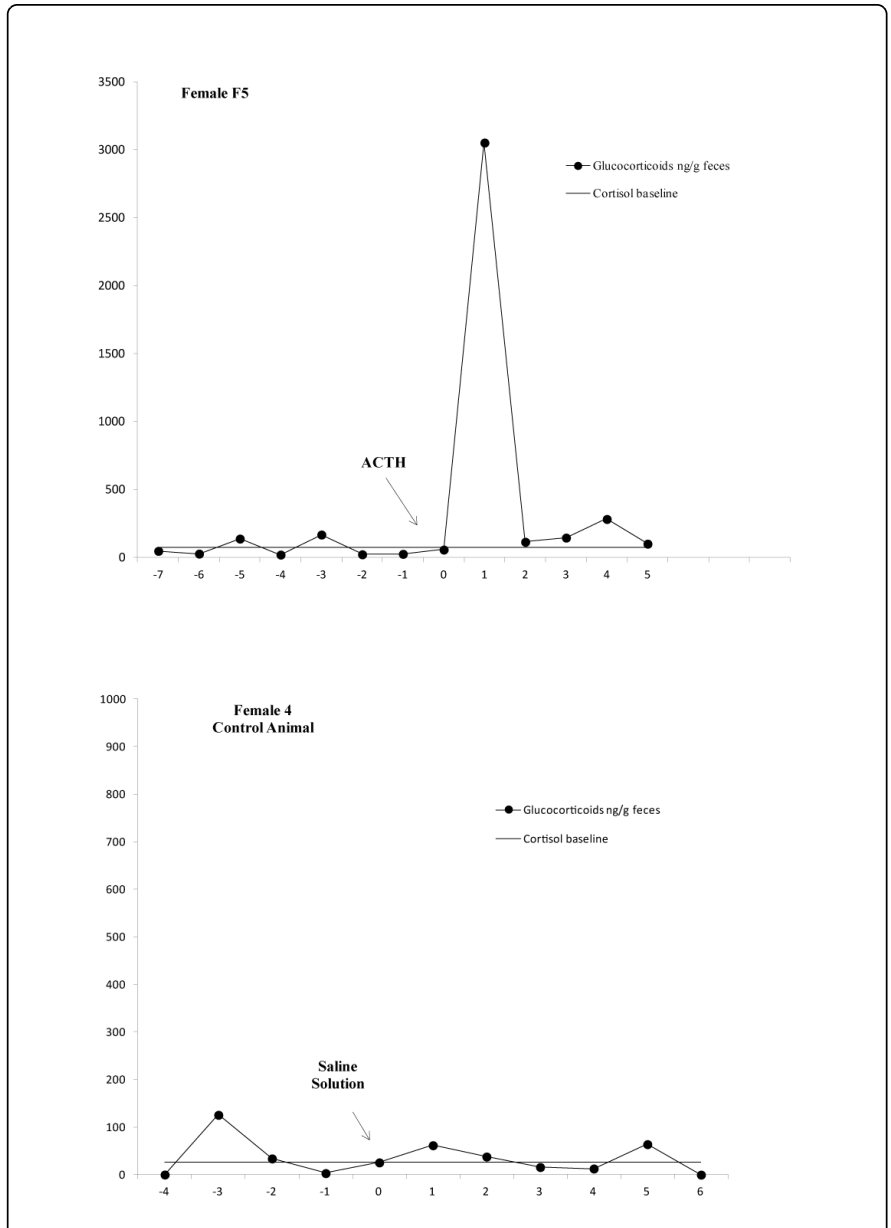

Figure 1: The circles indicate fecal glucocorticoids metabolite concentrations (ng/g feces) in crab-eating foxes before, during and after an ACTH challenge (F5) or saline injection (F4). The line indicates cortisol baseline concentrations for crab-eating foxes F5 and $\mathrm{F} 4$.

Concentrations of fecal glucocorticoid metabolites were significantly increased within a day of an ACTH challenge, indicating that adrenocortical activity can be monitored via fecal sample analyses in crab-eating fox using the cortisol R4866 antibody. Responses were robust in all treated individuals, representing a 10- to 40 -fold increase over pre-injection concentrations within $24-48 \mathrm{~h}$, with concentrations returning to baseline within a day of the peak. Palme et al. [22] suggested that the delay of fecal glucocorticoid excretion in sheep, ponies, and pigs roughly corresponds with gut transit time from duodenum to rectum. In crab-eating fox, the time lag of glucocorticoid excretion in feces appears to correspond with a food transit time of 24-48 $\mathrm{h}$ based on dye feeding of animals (Paz, unpublished).

\begin{tabular}{|l|l|l|l|}
\hline \multirow{2}{*}{ ANIMALS } & \multicolumn{3}{|l|}{ Mean ( \pm SEM) glucocorticoid concentrations (ng/g feces) } \\
\cline { 2 - 4 } & $\begin{array}{l}\text { Before ACTH or saline } \\
\text { injection }\end{array}$ & $\begin{array}{l}\text { After ACTH or saline } \\
\text { injection }\end{array}$ & Peak1 \\
\hline Control F4 & $37.8 \pm 51.3(5)$ & $28.6 \pm 22.6(5)$ & $61.9(1)$ \\
\hline Female F5 & $66.6 \pm 57.2(8)$ & $164.0 \pm 83.2(4)$ & $3055.7(1)$ \\
\hline
\end{tabular}


Citation: Rodrigues da Paz RC, Souza NP, Brown JL (2014) Evaluation of Glucocorticoid Faecal Monitoring as a Non-Invasive Assessment of Stress in Captive Crab-Eating Fox (Cerdocyoun thous) After ACTH Stimulation. J Steroids Hormon Sci S12: 008. doi: 10.4172/2157-7536.S12-008

Page 3 of 3

\begin{tabular}{|l|l|l|l|}
\hline Male $\mathrm{M}^{1}$ & $63.9 \pm 66.9(8)$ & $46.2 \pm 11.2(4)$ & $681.5(1)$ \\
\hline Male $\mathrm{M}^{2}$ & $123.0 \pm 122.2(8)$ & $55.99 \pm 30.5(5)$ & $1178.4(1)$ \\
\hline
\end{tabular}

7. de Villiers MS, van Jaarsveld AS, Meltzer DG, Richardson PR (1997) Social dynamics and the cortisol response to immobilization stress of the African wild dog, Lycaonpictus. HormBehav 31: 3-14.

Table 1: Mean \pm SEM fecal glucocorticoids concentrations (ng/g feces) before (days 1-8) and after (days 10-14) an ACTH or saline challenge in crab-eating fox males and females.

${ }^{1}$ Peak concentrations occurred on Day 9.

${ }^{2}$ Numbers in parentheses refer to number of fecal samples.

In summary, the physiological relevance of our cortisol EIA to assess adrenal activity in crab-eating foxes was proven valid by demonstrating that concentrations of fecal glucocorticoid metabolites were significantly increased following an ACTH challenge. From these findings we conclude that fecal samples can be used for the noninvasive assessment of adrenocortical status in crab-eating fox.

\section{Acknowledgments}

We thank UFMT Zoo staff for providing a crab-eating fox for the experiments. We are also grateful to Sara Putman and Nicole Presley for patient laboratory assistance. This research was funded by FAPEMAT, CAPES and SMITHSONIAN CBI.

\section{References}

1. Pessuti C, Santiago MEB, Oliveira LTF (2001) Order carnivore, family canidae (dogs, foxes, maned wolf) In: Folwer, M.E.; Cubas, Z.S. (Eds). Biology, Medicine, and Surgery of South American Wilde Animals: Iowa State University Press: 279-285.

2. Souza NP, Furtado PV, da Paz RC (2012) Non-invasive monitoring of the estrous cycle in captive crab-eating foxes (Cerdocyon thous). Theriogenology 77: 233-239.

3. Courtenay O, Maffei L (2004) Crab-eating fox Cerdocyon thous (Linnaeus, 1766). In: Canid Action Plan. Gland, Switzerland: IUCN Publications: $32-38$

4. Rocha VJ, Reis NR, Sekiama ML (2004) Dieta e dispersão de sementesporCerdocyon thous (Linnaeus) (Carnívora, Canidae), em um fragmentoflorestal no Paraná, Brasil. RevistaBrasileira de Zoologia. 21:871-876

5. Pedó E, Tomazzoni AC, Hertz SM, Christoff AU (2006) Diet of crabeating fox, Cerdocyon thous (Linnaeus) (Carnivora, Canidae), in a suburban area of southern Brazil. RevistaBrasileira de Zoologia 23: 637-641.

6. Gomes MS (2007) Carnívora - Canidae (Lobo-guará, Cachorro-do-mato, Raposa-do-campo). In: CubasZS, Silva JCR, Dias JLC (Eds). Tratado de AnimaisSelvagens: Medicina Veterinária. São Paulo: Roca: 492-504.

8. Sousa MB, Ziegler TE (1998) Diurnal variation on the excretion patterns of fecal steroids in common marmoset (Callithrixjacchus) females. Am J Primatol 46: 105-117.

9. Whitten PL, Stavisky R, Aureli F, Russell E (1998) Response of fecal cortisol to stress in captive chimpanzees (Pan troglodytes). Am J Primatol 44: 57-69.

10. Palme R, Mostl E (1997) Measurement of cortisol metabolites in faeces of sheep as a parameter of cortisol concentration in blood. Int J Mamm Biol 62: 192-197.

11. Palme R, Robia C, Baumgartner W, Möstl E (2000) Transport stress in cattle as reflected by an increase in faecal cortisol metabolite concentrations. Vet Rec 146: 108-109.

12. Graham LH, Brown JL (1996) Cortisol metabolism in the domestic cat and implications for non-invasive monitoring of adrenocortical function in endangered felids. Zoo Biol 15: 71-82.

13. Graham LH, Brown JL (1997) Non-invasive assessment of gonadal and adrenocortical function in felid species via fecal steroid analysis. Int J Mamm Biol 62: 78-82.

14. Jurke MH, Czekala NM, Lindburg DG, Millard SE (1998) Fecal cortcoid metabolite measurement in the cheetah (Acinonyxjubatus). Zoo Biol 16: 133-147.

15. Monfort SL, Mashburn KL, Brewer BA, Creel SR (1998) Evaluating adrenal activity in African wild dogs (Lycaonpictus) by fecal corticosteroid analysis. J Zoo Wildl Med 29: 129-133.

16. Touma C, Sachser N, Möstl E, Palme R (2003) Effects of sex and time of day on metabolism and excretion of corticosterone in urine and feces of mice. Gen Comp Endocrinol 130: 267-278.

17. Kotrschal K, Hirschenhauser K, MÖSTL E (1998) The relationship between social stress and dominance is seasonal in greylag geese AnimBehav 55: 171-176.

18. Goymann W, Möstl E, Gwinner E (2002). Corticosterone metabolites can be measured noninvasively in excreta of European stonechats, Saxicolatorquatarubicola. Auk 119: 1167-1173.

19. Wasser SK, Hunt KE, Brown JL, Cooper K, Crockett CM, et al. (2000) A generalized fecal glucocorticoid assay for use in a diverse array of nondomestic mammalian and avian species. Gen Comp Endocrinol 120: 260-275.

20. INPE/CPTEC (2009) National Institute for Space Research/Center for Weather Forecasting and Climate Studies, Ministry of Science and Technology, Brazil.

21. Schwarzenberger F, Son CH, Pretting R, Arbeiter K. (1996) Use of groupspecific antibodies to detect fecal progesterone metabolites during the estrus cycle of cows. Theriogenology 46: 23-32.

22. Palme R, Fischer P, Schildorfer H, Ismail MN (1996) Excretion of infused $14 \mathrm{C}$-steroid hormones via faeces and urine in domestic livestock. Animal Reproduction Science 43: 43-63. 